\title{
A eficiência conservacionista de medidas de recuperação de áreas degradadas: proposta metodológica
}

\author{
RICARDO V ALCARCEL ${ }^{* *}$ \\ ZILANDA DE SouZa SILVA***
}

\begin{abstract}
RESUMO
A recuperação de áreas degradadas encontra-se em fase de grande prosperidade tecnológica no pais, principalmente no que concerne às medidas de reabilitação. As metodologias utilizadas adotam postulados teóricos, que combinam aspectos que vão desde as necessidades ambientais das áreas até linhas filosóficas adquiridas nas diferentes escolas de formação acadêmica. Os resultados ambientais são diversos e de difícil comparação. A proposta deste estudo é sugerir formas de avaliação da eficácia conservacionista das medidas mitigadoras de impactos ambientais, utilizando o surgimento espontâneo de plantas, como parâmetro bio-indicador do processo de recuperação ambiental de uma área degradada. A idéia foi construída sobre resultados obtidos em área degradada, cujo decapeamento médio foi de $13 \mathrm{~m}$, que vem sendo recuperada desde 1993 pelos técnicos do Laboratório de Manejo de Bacias Hidrográficas da UFRRJ.
\end{abstract}

Palavras-chave: indicador biológico, propriedades emergentes

\begin{abstract}
Ecological evaluation of some land reclamation techniques: a methodological approach. The study of land reclamation is now intensive in Brazil, mainly in relation to the rehabilitation process. Usually, the methodology utilised are based in theory and combine different aspects: environment response and philosophical point of view from different work groups. Then, the environment results obtained are diverse and difficult to be compared. The subject of this study is to suggest new ways to evaluate the conservation efficacy of a variable used in land reclamation projects. We suggest the utilisation of a spontaneous establishment of plants, as a biological indicator in the environmental recovery of degraded area. The idea was constructed with results obtained in a land reclamation area since 1993, in which an average of $13 \mathrm{~m}$ of soil profile was removed.
\end{abstract}

\footnotetext{
* Apoio Sepetiba Engenharia e Comércio Ltda.

*** Prof.Adjunto UFRRJ C.P.74.529 CEP 23.851-970 Seropédica, RJ

Biologa C.P. 74.529 CEP 23.851-970 Seropédica, RJ
} 
Key words: biological indicator, establishment attribute.

\section{INTRODUÇÃO}

As atividades antrópicas, quando desenvolvidas desordenadamente, sem tomar em consideração aspectos conservacionistas, acarretam a degradação dos ecossistemas. Os deslizamentos, enchentes, processos erosivos acelerados e as áreas de empréstimo são evidências do uso inapropriado dos recursos naturais.

A demanda de conhecimento gerada pela sociedade, para reversão dos problemas ambientais, tem suscitado a criação de novas técnicas e estratégias de recuperação e de reabilitação de áreas degradadas, assim como dos ecossistemas intensamente modificados pela atividade antrópica.

As instituições de ensino, pesquisa e extensão têm respondido de forma ágil às demandas da sociedade, como pode ser observado nas abordagens técnicas, mérito científico e número de trabalhos publicados nos anais dos últimos eventos específicos sobre o tema (UFRRJ,1991; UFPR 1992 e 1994).

O uso de princípios teóricos da sucessão vegetal, em ecossistemas degradados, constitui uma importante ferramenta para sua reabilitação, pois se está utilizando os próprios mecanismos da natureza local, induzindo o surgimento de novos estágios sucessionais.

A reabilitação de áreas degradadas deve envolver um conjunto de fatores ambientais, de tal forma que propicie condições para que os processos ambientais, sejam similares ao de uma vegetação secundária da região, tanto nos aspectos hidrológicos, fitossociológico, ciclagem de nutrientes, "construção de solo", filtragem de radiação solar, umidade, microclima e meso-fauna dos compartimentos do ecossistema: parte aérea, serrapilheira e substrato.

O uso da colonização espontânea de espécies vegetais, como variável de amostragem do nível de reabilitação do ecossistema degradado, reflete o grau de acerto da reabilitação do ecossistema degradado, pois as plantas só se estabelecem, sucedendo-se umas às outras, em função das próprias propriedades emergentes que elas mesmas geram no ecossistema: disponibilidade de água, luz, temperatura, matéria orgânica, radiação solar e construção do solo.

Na presente proposta metodológica, apresenta-se e sugere-se estratégias de usar os mesmos princípios para avaliar a eficiência conservacionistas das medidas mitigadoras implantadas.

Utilizou-se como laboratório de observação a área experimental do Laboratório de Manejo de Bacias Hidrográficas da UFRRJ, situada na Ilha da Madeira, município de Itaguaí, RJ. Ela é uma típica área de empréstimo, onde retirou-se aproximadamente $1.10^{6} \mathrm{~m}^{3}$ de aterro para construção do Porto de Sepetiba. 


\section{MATERIALE MÉTODOS}

A área de estudo situa-se na região denominada de Costa Verde, distrito

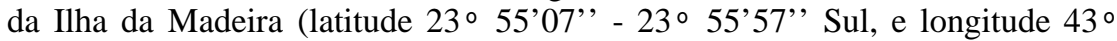
49'73' - 43॰ 50'33' 'Oeste), no município de Itaguaí, Estado do Rio de Janeiro. Ela possui 10,81ha de superfície. O clima da região é classificado como "Aw" (tropical chuvoso com inverno seco) segundo a classificação de KÖPPEN (1938).

As principais classes de solos encontrados na região são os Podzólicos nas vertentes, subclasse Podzólico Vermelho Amarelo Distrófico e Hidromórfico, subclasse Glei Humico nas áreas de várzeas.

A área de estudo pertence ao domínio ecológico da Mata Atlântica e encontra-se entre duas importantes formações ecológicas: Manguezal e Floresta Secundária de Restinga em estado inicial de sucessão (VALCARCEL, 1994).

$\mathrm{O}$ relevo na área de empréstimo é acidentado, com substrato inconsistente, rígido quando seco e friável quando úmido. Apresenta 0,55ha de afloramento rochoso.

\section{PROCESSO DE DEGRADAÇÃO E REABILITAÇÃO DA ÁREA}

A área foi decapeada entre os anos de 1978 a 1980, para a construção do Porto de Sepetiba. Nas drenagens e locais onde o processo erosivo foi acelerado, alcançou profundidade de $27 \mathrm{~m}$, promovendo a desfiguração da topografia remanescente, destruindo os acessos internos.

A cronologia dos processos de recuperação espontânea pode ser resumida da seguinte forma:

a) histórico da região antes de $1970 \rightarrow$ local de produção agrícola de subsistência, com solos exauridos e baixa produtividade. Predomínio de plantação de milho e de banana;

b) retirada de terra entre 1979-1980 $\rightarrow$ atividade de máxima degradação, uso de maquinário pesado para remoção de substrato;

c) abandono da área entre 1981-1983 $\rightarrow$ com processo erosivo acelerado - o material solto é facilmente transportado foi carreado para a Baía de Sepetiba em grande quantidade;

d) abandono da área 1984-1992 $\rightarrow$ processo erosivo com tênue equilíbrio, chuvas com baixa intensidade ainda carreavam sedimentos;

e) recuperação da área 1993 - $1996 \rightarrow$ o Laboratório de Manejo de Bacias Hidrográficas começou seus trabalhos de pesquisa e de recuperação. Já observa-se equilíbrio incipiente dos processos erosivos, registrado pelo volume de sedimentos e de espécies que colonizam espontaneamente a área. 
De acordo com os fatores que influem no geodinamismo torrencial do local, estabeleceu-se o conceito de "áreas - tipo", onde agrupou-se regiões com processos erosivos e características geomorfológicas similares. Elas foram classificadas em função da combinação do Relevo com a magnitude dos processos erosivos em: relevo acidentado, relevo suave, voçorocas, áreas de drenagens e áreas aluviais. (Ver figura 1).

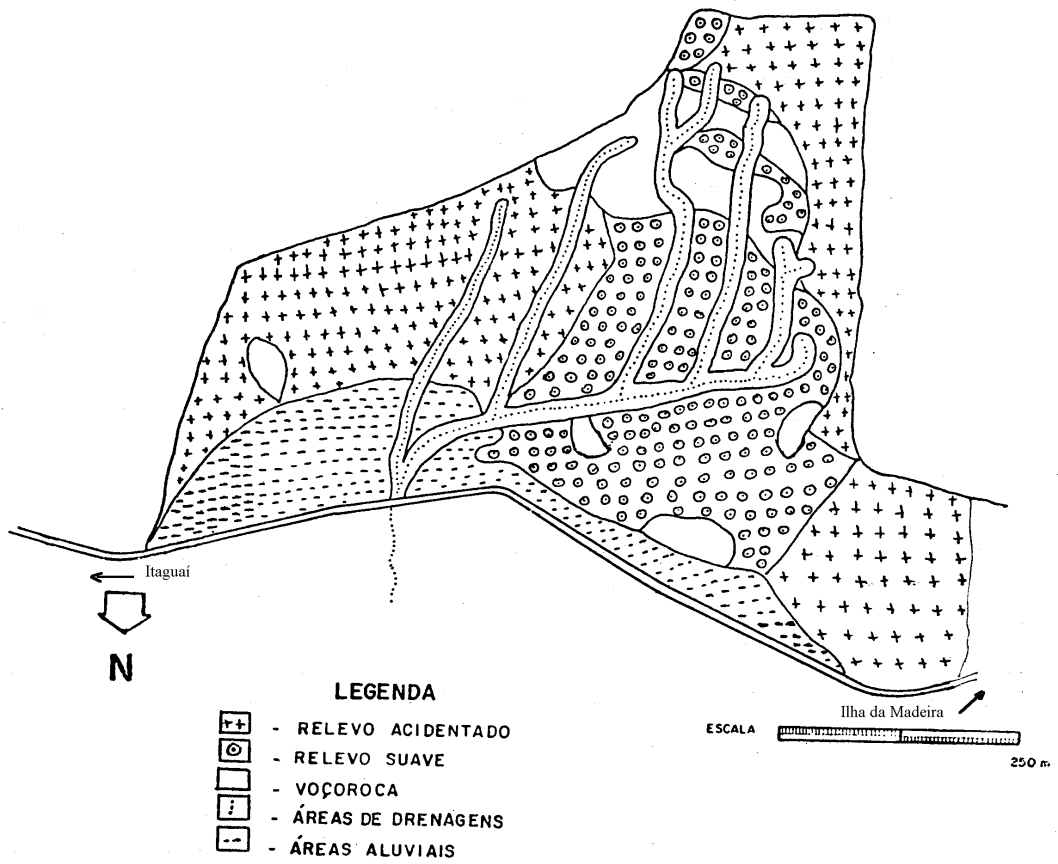

FIGURA 01: Distribuição das áreas-tipo

Para a estabilização do geodinamismo torrencial, implantou-se as medidas mitigadoras classificadas em: medidas físicas, físico-biológicas e biológicas (VALCARCEL, 1994), com o objetivo de reverter os problemas ambientais a curto, médio e longo prazo.

As medidas mitigadoras foram implantadas de forma diferenciada em cada uma das áreas-tipo. Cada variação metodológica das medidas foi individualizada e considerada como um tratamento. Elas totalizam 40 tratamentos (Quadro 1). 
Quadro 1 - Medidas conservacionistas

\begin{tabular}{|c|c|c|c|c|}
\hline & & \multicolumn{3}{|c|}{ Medidas Conservacionistas } \\
\hline Área-tipo & Test. (cód.) & Biológicas & Físicas & $\begin{array}{c}\text { Físico - } \\
\text { Biológicas }\end{array}$ \\
\hline \multicolumn{5}{|c|}{1 - RELEVO $\quad$ ACIDENTADO } \\
\hline $\begin{array}{l}\text { 1.1-Substrato } \\
\text { adensado }\end{array}$ & $\mathrm{T} 1.1$ & $\begin{array}{c}\text { B1 Plantio de sabiá } \\
\text { B2 Plantio de } \\
\text { várias } \\
\text { espécies }\end{array}$ & -- & $\begin{array}{c}\text { FB1 Almofada } \\
(2 \mathrm{~m}) \\
\text { FB2 Almofada } \\
(4 \mathrm{~m}) \\
\text { FB3 Almofada } \\
(8 \mathrm{~m})\end{array}$ \\
\hline $\begin{array}{l}\text { 1.2-Substrato não } \\
\text { adensado }\end{array}$ & T1.2 & $\begin{array}{c}\text { B3 Capim jaraguá } \\
\text { B4 Plantio de } \\
\text { Albizia } \\
\text { lebbek }\end{array}$ & F1 Calha de captação & -- \\
\hline 2-RELEVO & \multicolumn{4}{|l|}{ SUAVE } \\
\hline $\begin{array}{c}\text { 2.1-Profundida de } \\
>40 \mathrm{~cm}\end{array}$ & $\mathrm{~T} 2.1$ & $\begin{array}{c}\text { B5 Plantio de } \\
\text { várias } \\
\text { espécies }\end{array}$ & $\begin{array}{l}\text { F2 Calhas de cap- } \\
\text { tação }\end{array}$ & $\begin{array}{l}\text { FB4 } \\
\quad \text { Almofadas }\end{array}$ \\
\hline 2.2-Prof. $\leq 40 \mathrm{~cm}$ & $\mathrm{~T} 2.2$ & -- & F3 Muro de desvio & \begin{tabular}{|l|} 
FB5 \\
$\quad$ Almofadas \\
\end{tabular} \\
\hline \multicolumn{5}{|l|}{ 3- VOÇOROCAS } \\
\hline $\begin{array}{l}\text { 3.1-Voçorocas } \\
\text { ativas }\end{array}$ & T3.1 & $\begin{array}{l}\text { B6 Plantio de } \\
\text { Cecropia } \text { sp. }\end{array}$ & $\begin{array}{r}\text { F4 Calhas de } \\
\text { captação }\end{array}$ & $\begin{array}{l}\text { FB6 } \\
\quad \text { Almofadas }\end{array}$ \\
\hline $\begin{array}{l}\text { 3.2-Voçorocas } \\
\text { passivas }\end{array}$ & T3.2 & $\begin{array}{c}\text { B7 Plantio de } \\
\text { várias } \\
\text { espécies }\end{array}$ & $\begin{array}{r}\text { F5 Calhas de } \\
\text { captação }\end{array}$ & \begin{tabular}{|l} 
FB7 \\
\\
$\quad \begin{array}{l}\text { Almofad } \\
\text { as }\end{array}$ \\
\end{tabular} \\
\hline \multicolumn{5}{|l|}{ 4 - DRENAGENS } \\
\hline $\begin{array}{l}\text { 4.1-Drenagem } \\
\text { principal }\end{array}$ & -- & -- & $\begin{array}{l}\text { F3 Muro de desvio } \\
\text { F6 Diques }(\mathrm{m} / \mathrm{j}) \\
\text { F7 Travessas }(\mathrm{m} / \mathrm{j}) \\
\text { F8 Espigões }(\mathrm{m} / \mathrm{j}) \\
\text { F9 Muros laterais } \\
\text { F10 Praça de } \\
\quad \text { sedimentação } \\
\quad(\mathrm{m} / \mathrm{j}) \\
\end{array}$ & -- \\
\hline $\begin{array}{l}\text { 4.2-Drenagens } \\
\text { secundárias }\end{array}$ & -- & -- & $\begin{array}{r}\text { F11 Calhas de } \\
\text { captação }\end{array}$ & -- \\
\hline 5-ÁREA & \multicolumn{4}{|l|}{ ALUVIAL } \\
\hline 5.1-Leito fixo & $\begin{array}{l}\text { T5.1a } \\
\text { T5.1b } \\
\text { T5.1c }\end{array}$ & $\begin{array}{c}\text { B8 Plantio de } \\
\text { várias } \\
\text { espécies }\end{array}$ & -- & -- \\
\hline 5.2-Leito removível & T5.2 & $\overline{--}$ & -- & $\overline{--}$ \\
\hline Total & 10 & 08 & 15 & 07 \\
\hline
\end{tabular}

Nota: as almofadas apresentam espaçamentos diferenciados 
As medidas foram empregados em áreas-tipos, totalizando 33 unidades amostrais (Quadro 2), sendo que algumas delas foram deixadas como testemunhas, com ausência de medidas conservacionistas. Esta estratégia objetiva permitir a avaliação comparativa de eficiência conservacionista entre tratamentos aplicados à mesma área-tipo, em áreas-tipo diferentes e entre tratamentos e testemunha.

Quadro 2 - Unidades amostrais

\begin{tabular}{|c|c|c|c|}
\hline Número & $\begin{array}{l}\text { Tratamento } \\
\text { (código) }\end{array}$ & Medidas conservacionistas & Área Tipo \\
\hline \multicolumn{4}{|c|}{ Testemunha } \\
\hline 01 & $T 1.1$ & Substrato adensado & Relevo acidentado \\
\hline 02 & $T 1.2$ & Substrato não adensado & $\sim$ \\
\hline 03 & $T 2.1$ & Profundidade $>40 \mathrm{~cm}$ & Relevo suave \\
\hline 04 & $\mathrm{~T} 2.2$ & Profundidade $\leq 40 \mathrm{~cm}$ & $\sim$ \\
\hline 05 & T3.1 & Voçoroca ativa & Voçoroca \\
\hline 06 & T3.2 & Voçoroca passiva & $\sim$ \\
\hline 07 & $\mathrm{~T} 5.1 \mathrm{a}$ & $\begin{array}{l}\text { Leito fixo com plantio de espécies } \\
\text { arbóreas e sem pastoreio }\end{array}$ & Área Aluvial \\
\hline 08 & $\mathrm{~T} 5.1 \mathrm{~b}$ & Leito fixo sem plantio e sem pastagem & $\sim$ \\
\hline 09 & $\mathrm{~T} 5.1 \mathrm{c}$ & $\begin{array}{l}\text { Leito fixo sem plantio de espécies } \\
\text { arbóreas, com pastoreio }\end{array}$ & $\sim$ \\
\hline 10 & T5.2 & Leito removível & $\sim$ \\
\hline \multicolumn{4}{|c|}{ Medidas biológicas } \\
\hline 11 & B1 & Plantio de sabiá & $\begin{array}{c}\text { Relevo acidentado com } \\
\text { substrato adensado }\end{array}$ \\
\hline 12 & $\mathrm{~B} 2$ & $\begin{array}{c}\text { Plantio de várias espécies (“coquetel } \\
\text { de mudas") }\end{array}$ & $\sim$ \\
\hline 13 & B3 & Capim jaraguá & $\begin{array}{l}\text { Relevo acidentado com } \\
\text { substrato não adensado }\end{array}$ \\
\hline 14 & B4 & Plantio de Albizia lebbek em faixa & $\sim$ \\
\hline 15 & B5 & Plantio de várias espécies & $\begin{array}{l}\text { Relevo suave com } \\
\text { profundidade }>40 \mathrm{~cm}\end{array}$ \\
\hline 16 & B6 & Plantio de Cecropia sp. & Voçoroca ativa \\
\hline 17 & B7 & Plantio de várias espécies & Voçorocas passivas \\
\hline 18 & B8 & Plantio de várias espécies & Área aluvial leito fixo \\
\hline \multicolumn{4}{|c|}{ Medidas físicas } \\
\hline 19 & F6m & Diques (a montante) & Drenagem principal \\
\hline 20 & F6j & Diques (a jusante) & $\sim$ \\
\hline 21 & F7m & Travessas (a montante) & $\sim$ \\
\hline 22 & $\mathrm{~F} 7 \mathrm{j}$ & Travessas(a jusante) & $\sim$ \\
\hline 23 & F8m & Espigões (a montante) & $\sim$ \\
\hline 24 & F8j & Espigões (a jusante) & $\sim$ \\
\hline 25 & F10m & Praça de sedimentação (a montante) & $\sim$ \\
\hline 26 & $\mathrm{~F} 10 \mathrm{j}$ & Praça de sedimentação (a jusante) & $\sim$ \\
\hline
\end{tabular}




\begin{tabular}{|c|l|l|c|}
\hline \multicolumn{3}{|c|}{ Medidas físico-biológicas } \\
\hline 27 & FB1 & Almofadas/espaçamento (2 m) & $\begin{array}{c}\text { Relevo acidentado com } \\
\text { substrato adensado }\end{array}$ \\
\hline 28 & FB2 & Almofadas/espaçamento (4 m) & $\sim$ \\
\hline 29 & FB3 & Almofadas/espaçamento $(8 \mathrm{~m})$ & $\sim$ \\
\hline 30 & FB4 & Almofadas & $\begin{array}{c}\text { Relevo suave com } \\
\text { profundidade }>40 \mathrm{~cm}\end{array}$ \\
\hline 31 & FB5 & $\sim$ & $\begin{array}{c}\text { Relevo suave com } \\
\text { profundidade } \leq 40 \mathrm{~cm}\end{array}$ \\
\hline 32 & FB6 & $\sim$ & Voçorocas ativas \\
\hline 33 & FB7 & $\sim$ & Voçorocas passivas \\
\hline
\end{tabular}

\section{SUCESSÃO VEGETAL}

O processo de sucessão ecológica inicia-se em áreas disponíveis a colonização, tendo como as espécies colonizadoras as "pioneiras", espécies dependentes de luz, intolerantes à sombra, possuem crescimento rápido, vida curta, alta dispersão de semente pelo vento e por animais. As espécies tropicais mais comuns são Ochrora lagopus, Cecropia spp., Trema micrantha, Schizolobium parahybum, Jacarandá copaia e outras (KAGEYAMA et al. 1990).

As espécies de transição possuem crescimento lento, intolerância a luz, florescimento e frutificação tardios, baixa produção de sementes, difícil dispersão e grande porte. Neste estágio a comunidade se torna mais heterogênea; as famílias mais abundantes do bioma são Myrtaceae, Lauraceae, Rubiaceae, Sapotaceae e Euphorbiaceae (LEITÃO-FILHO, 1993).

O estágio final de uma comunidade é mais evoluído e equilibrado. As espécies crescem lentamente, têm ciclo de vida longo, são tolerantes à sombra. $\mathrm{O}$ solo possui grande quantidade de matéria orgânica proveniente das camadas vegetais superiores, o solo é pobre em vegetação rasteira. A vegetação arbórea forma um dossel fechado, com presença de lianas e epífitas.

\section{PROPOSTA METODOLÓGICA}

A proposta metodológica define uma estratégia operacional de trabalho de campo e laboratório, estabelecendo um programa de monitoramento da dinâmica da sucessão vegetal em áreas de empréstimo, com e sem medidas conservacionistas.

Os resultados destas avaliações indicarão as espécies mais aptas que se enquadram na dinâmica sucessional de áreas de empréstimo. Esta tecnologia é mais econômica e mais rápida, podendo ser estendida para os ecossistemas degradados da região de domínio ecológico da Mata Atlântica.

Com a implantação das medidas conservacionistas na área, a dinâmica dos processos erosivos foi reduzida sensivelmente, alcançando uma fase de equilíbrio estável. As medidas físico-biológicas e biológicas estão proporcionando cobertura vegetal e matéria orgânica para o substrato, dando condições para o desenvolvimento das espécies vegetais.

Considerando as medidas conservacionistas como tratamento, definiu-se parcelas amostrais no centro dos 33 tratamentos, onde o monitoramento da 
evolução do surgimento das espécies espontâneas deverá ser realizado periodicamente.

Os métodos fitossociológicos de caracterização das comunidades vegetais são próprios para ambientes ecológicos específicos. Eles são utilizados para levantamento fitossociológicos em áreas com diferentes estágios sucessionais (BRAUN-BLANQUET, 1979; GAETA et al.,1989; GOETZKE, 1990 e LEITÃO FILHO, 1993).

No processo de recuperação de áreas degradadas, observa-se a ocorrência simultânea de sucessão primária e secundária, em áreas especialmente próximas. Um levantamento fitossociológico adaptado a estas peculiaridades é de difícil consecução. Optamos pela escolha do "Método de Pontos", por reunir: representatividade da vegetação e ser operacionalmente prático, além de causar menos perturbações à vegetação, tendo em vista o elevado número de unidades amostrais.

O método consiste em levantar o número de toques das espécies em uma vara vertical graduada até $1,5 \mathrm{~cm}$ e $0,5 \mathrm{~cm}$ de diâmetro. A cada toque, registra-se a espécie, sua altura e observações gerais. Sendo considerado indivíduo toda e qualquer parte do sistema aéreo da planta sobre o solo, ainda que subterraneamente possa haver ligação entre si por meio do rizoma, ou constituírem ramos de um indivíduo (ORMOND, 1960 apud SILVA, 1991). Este método permite amostrar espécies de porte herbáceo, trepadeiras e arbustivas, dependendo da especificação e graduação da vara (CASTELLANI \& STUBBLEBINE, 1993).

Os parâmetros fitossociológicos considerados e suas respectivas fórmulas são:

Média de toques

$$
\mathrm{MT}=\mathrm{NT} / \mathrm{NP}
$$

Freqüência ou cobertura absoluta $\quad F A=100 . N P / N T P$

Freqüência ou cobertura relativa $\quad \mathrm{FR}=100 . \mathrm{FA} / \Sigma \mathrm{FA}$

Frequiência ou cobertura na área $\quad \mathrm{CR}=(100-\mathrm{No})$. FA/ $\Sigma \mathrm{FA}$

Densidade relativa $\quad \mathrm{DR}=100 . \mathrm{N} / \mathrm{n}$

Vigor absoluto $\mathrm{VA}=100 . \mathrm{NT} / \mathrm{NTP}$

Vigor relativo $\quad \mathrm{VR}=100 . \mathrm{VA} / \Sigma \mathrm{VA}$

Índice de Valor de Importância $\quad \mathrm{IVI}=\mathrm{FR}+\mathrm{DR}+\mathrm{VR}$

Índice de Valor de Cobertura

$\mathrm{IVC}=\mathrm{FA}+\mathrm{VA}$

onde:

NT = número de toques da espécie considerada

NP= número de pontos com a espécie considerada

NTP = número total de pontos

No= porcentagem de pontos sem toques

$\mathrm{n}=$ número de indivíduos da espécie considerada

$\mathrm{N} \quad=$ número total de indivíduos amostrados

$\Sigma \quad=$ somatório 
Experimentalmente obteve-se tamanho mínimo representativo da vegetação de uma área-tipo (relevo acidentado) com 180 pontos (FRANCÊS \& VALCARCEL, 1995). O intervalo de distância, para fins de amostragem, entre pontos foi de $0,5 \mathrm{~m}$, determinando-se uma área amostral mínima de $45 \mathrm{~m}^{2}$ (Figura 2).

Figura 2: Amostragem e curva do coletor

a) Amostragem sistemática

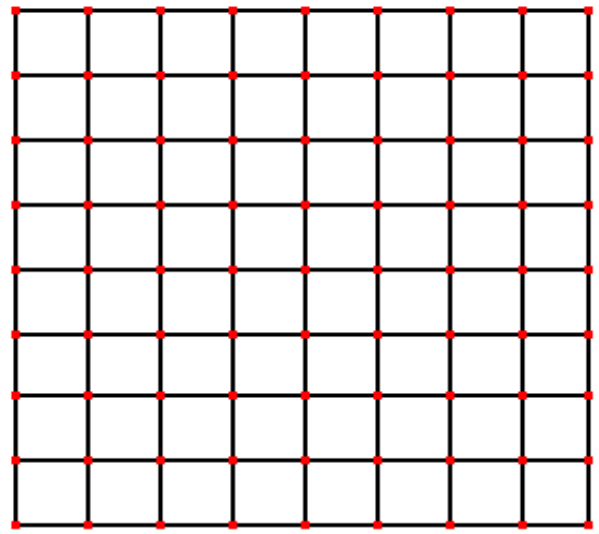

— $1,0 \mathrm{~m}$

b) Curva do coletor (FRANÇES \& VALCARCEL, 1995)

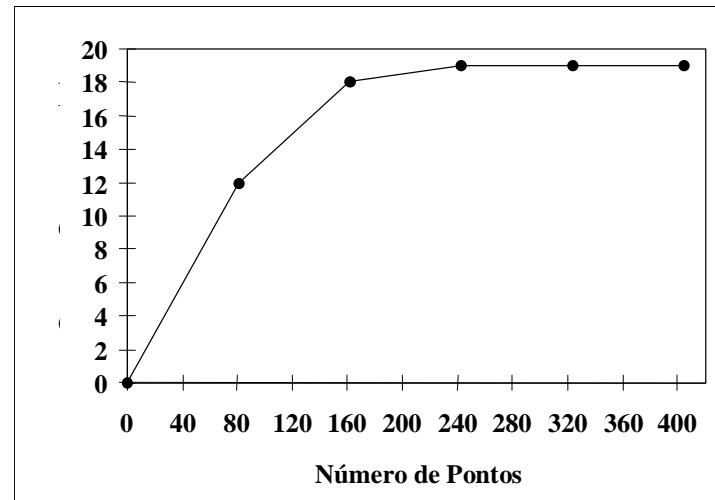


A amostragem do mesmo indivíduo mais de uma vez (trepadeira por exemplo), será contabilizada através da média do número de toques em cada ponto. Esta informação será processada individualmente e representará o vigor da espécie (SILVA, 1991).

Os dados deverão ser levantados (Quadro 3 e 4) com periodicidade estacional; serão analisados de forma a gerar gráficos elucidativos (Quadro 5) das variações fitossociológicas das comunidades vegetais, parâmetros estes que avaliam a eficiência conservacionista entre: a) tratamento e testemunha; b) tratamentos diferentes em uma mesma área-tipo e c) tratamentos similares em áreas-tipos diferentes.

Quadro 3 - Dados básicos

\begin{tabular}{|c|c|c|c|}
\hline Tratamento: & Data: & Coletor: & \\
\hline $\begin{array}{l}\text { Ponto } \\
\text { n- }\end{array}$ & $\begin{array}{c}\text { Espécies } \\
\text { (nome/código) }\end{array}$ & $\begin{array}{l}\text { Toques } \\
\text { n- }\end{array}$ & $\begin{array}{c}\text { Altura } \\
\mathrm{Cm}\end{array}$ \\
\hline \multicolumn{4}{|l|}{1} \\
\hline & & & \\
\hline \multicolumn{4}{|c|}{2} \\
\hline & & & \\
\hline & & & \\
\hline \multicolumn{4}{|c|}{3} \\
\hline & & & \\
\hline \multicolumn{4}{|l|}{4} \\
\hline & & & \\
\hline & & & \\
\hline \multicolumn{4}{|l|}{5} \\
\hline & & & \\
\hline \multicolumn{4}{|c|}{6} \\
\hline & & & \\
\hline & & & \\
\hline \\
\hline & & & \\
\hline \\
\hline \multicolumn{4}{|l|}{. } \\
\hline \multicolumn{4}{|l|}{. } \\
\hline \multicolumn{4}{|l|}{. } \\
\hline . & & & \\
\hline \multicolumn{4}{|l|}{$\mathrm{n}$} \\
\hline- & & $\Sigma$ & \\
\hline
\end{tabular}


Quadro 4 - Dados complementares

\begin{tabular}{|c|c|c|c|c|c|c|c|c|c|c|}
\hline \multicolumn{4}{|c|}{ Tratamento: } & & \multicolumn{2}{|l|}{ Data: } & \multicolumn{4}{|c|}{ Coletor: } \\
\hline \multirow{2}{*}{\begin{tabular}{|r|} 
Ponto \\
no \\
\end{tabular}} & \multicolumn{2}{|c|}{ Serrapheira } & \multirow{2}{*}{$\begin{array}{c}\text { Expos. } \\
\text { Solar } \\
\text { Setor } \\
\text { no } \\
\end{array}$} & \multicolumn{2}{|c|}{ Pedregosidade } & \multirow[t]{2}{*}{ Sementes } & \multicolumn{2}{|c|}{ Microtopografia } & \multirow[t]{2}{*}{ Erosão } & \multirow[t]{2}{*}{ Musgos } \\
\hline & $\begin{array}{c}\text { Altura } \\
(\mathrm{cm})\end{array}$ & $\begin{array}{l}\text { cob. } \\
(\%)\end{array}$ & & $\begin{array}{l}\text { área } \\
(\%)\end{array}$ & tipo & & sulcos & forma & & \\
\hline \multicolumn{11}{|l|}{01} \\
\hline \multicolumn{11}{|l|}{02} \\
\hline \multicolumn{11}{|l|}{03} \\
\hline \multicolumn{11}{|l|}{04} \\
\hline \multicolumn{11}{|l|}{05} \\
\hline \multicolumn{11}{|l|}{06} \\
\hline \multicolumn{11}{|l|}{07} \\
\hline \multicolumn{11}{|l|}{08} \\
\hline \multicolumn{11}{|l|}{09} \\
\hline \multicolumn{11}{|l|}{10} \\
\hline \multirow{2}{*}{\multicolumn{11}{|c|}{$\dot{.}$}} \\
\hline & & & & & & & & & & \\
\hline & & & & & & & & & & \\
\hline \multicolumn{11}{|l|}{$n-1$} \\
\hline $\mathrm{n}$ & & & & & & & & & & \\
\hline
\end{tabular}

Nota:

\begin{tabular}{|c|c|c|c|c|c|c|}
\hline Serrapilheira & $\begin{array}{l}\text { Exposição } \\
\text { solar }\end{array}$ & Pedregosidade & Sementes & Micro-topografia & Erosão & Musgo \\
\hline Altura $(\mathrm{cm})$ & $\begin{array}{l}\text { Setor no- } \\
\text { I - Norte(n) } \\
\text { II - ne }\end{array}$ & $\begin{array}{l}\text { Tipo: } \\
\text { solta }(\mathrm{S}) \text {; } \\
\text { fixa }(\mathrm{F})\end{array}$ & \multirow{2}{*}{$\begin{array}{l}\text { Presença } \\
\text { (P) } \\
\text { Ausência } \\
\text { (A) }\end{array}$} & $\begin{array}{c}\text { Sulcos: } \\
\text { Presença(P) } \\
\text { Ausência(A) }\end{array}$ & \multirow[t]{2}{*}{$\begin{array}{l}\text { Presença (P) } \\
\text { Ausência(A) }\end{array}$} & \multirow[t]{2}{*}{$\begin{array}{l}\text { Presença (P) } \\
\text { Ausência } \\
\text { (A) }\end{array}$} \\
\hline \begin{tabular}{|l} 
Cobertura \\
(porcentage \\
$\mathrm{m}$, em área, \\
ocupada em \\
$10 \times 10 \mathrm{~cm}$, \\
ao redor do \\
ponto)
\end{tabular} & $\begin{array}{l}\text { III -Este (e) } \\
\text { IV- se } \\
\text { V - Sul(s) } \\
\text { VI - sw } \\
\text { VII-oeste(w) } \\
\text { VIII-nw }\end{array}$ & $\begin{array}{l}\text { Área: } \\
\text { porcentagem da } \\
\text { área ocupada em } \\
100 \mathrm{~cm}^{2} \text { ao redor } \\
\text { do ponto }\end{array}$ & & \begin{tabular}{|c|} 
Forma: \\
Côncavo(CC) \\
Convexo(CV) \\
Plano(P)
\end{tabular} & & \\
\hline
\end{tabular}


Quadro 5: Gráficos propostos

\begin{tabular}{|c|c|c|}
\hline Título & Abcissa & Ordenada \\
\hline $\begin{array}{l}\text { Distribuição do número de espécies por família no tratamento } \\
\text { "x". }\end{array}$ & Famílias & Espécies* (\%) \\
\hline $\begin{array}{l}\text { Distribuição do número de indivíduos por espécie no tratamento } \\
\text { " } \mathrm{x} \text { ". }\end{array}$ & Espécies* & $\mathrm{N}^{\circ}$ de indivíduos $(\%)$ \\
\hline Distribuição do número de toques por espécie no tratamento & Espécies* & $\mathrm{N}^{\mathrm{o}}$ de toques $(\%)$ \\
\hline $\begin{array}{l}\text { Relação entre o número de pontos e o número de toques no } \\
\text { tratamento "x". }\end{array}$ & $\mathrm{N}^{\circ}$ de toques & $\mathrm{N}^{\mathrm{o}}$ de pontos $(\%)$ \\
\hline $\begin{array}{l}\text { Distribuição do Índice de Valor de Importância (IVI) das famílias } \\
\text { amostradas no tratamento " } \mathrm{x} \text { ". }\end{array}$ & Famílias & $\operatorname{IVI}(\%)$ \\
\hline $\begin{array}{l}\text { Distribuição do Índice de Valor de Importância (IVI) das espécies } \\
\text { amostradas no tratamento " } \mathrm{x} \text { ". }\end{array}$ & Espécie* & IVI (\%) \\
\hline
\end{tabular}

Nota: A comparação entre tratamentos deve envolver o uso de histogramas sobrepostos, no eixo das abcissas. As espécies(*) com baixa magnitude dos índices deverão ser agrupadas em categoria especial.

\section{CONSIDERAÇÕES FINAIS}

A proposta apresentada contribui para o equacionamento metodológico de estudos de avaliação da eficiência conservacionista de medidas de recuperação de áreas degradadas. Ela permite acompanhamento da evolução dos processos de reabilitação ambiental. Ela é laboriosa, porém é objetiva e viável.

Ela constitui uma ferramenta importante para aferir quantitativamente a eficiência das medidas conservacionistas em relação a reabilitação ambiental, onde a composição florística e fitossociológica possuem papel de grande relevância.

Os resultados ambientais da implantação das medidas conservacionistas, durante o período de 1993 a 1996, são visualmente perceptíveis e hidrologicamente satisfatórios, porém quantitativamente precários. A presente metodologia constitui uma importante ferramenta para avaliar o surgimento de propriedades emergentes de difícil quantificação (intangíveis).

A proposta aponta uma estratégia, com início, meio e fim. Facilitando a tomada de decisão quando a metodologia de avaliação a ser utilizada para monitoramento da composição florística da área de empréstimo. Ela não esgota o assunto, trata-se apenas de uma contribuição metodológica, no sentido de ajustar a variação das propriedades emergentes decorrentes das medidas conservacionistas implantadas em ecossistema degradado.

As magnitudes dos dados fitossociológicos, analisadas dentro do contexto das medidas conservacionistas implantadas, evidenciam o grau de acerto 
das operações desenvolvidas e podem colaborar no aperfeiçoamento e desenvolvimento de novas medidas conservacionistas.

\section{BIBLIOGRAFIA CITADA}

BRAUN-BLANQUET,J. Fitossociologia. Bases para el estudio de las comunidades vegetales. HBLUME Ed. (trad. Jorge Halucat Jo). Madri. Espanha. 1979. 820p.

CASTELLANI, T.T. \& STUBBLEIBINE, W.H.Sucessão Secundária Inicial em Mata Tropical Mesófila, após Pertubação por Fogo. Rev Bras. Bot. 16(2), 1993. 181-302.

FRANCÊS, H.J.S. \& VALCARCEL, R. Medidas Físico-Biológicas de Recuperação de Áreas Degradadas: Almofadas. Relatório Final do CNPq, Itaguaí, RJ, 1995.

GAETA, M.M., POMPÉIA, S.L. MENDONÇA, R.R., SINISGALI, P.A. de A., MARTINS, S.E., MENEGUETTI, A.M.L. \& CURY, M. Aspectos Fitossociológicos da Vegetação da Serra do Mar Degradada pela Poluição Atmosférica de Cubatão. CETESB. São Paulo, SP, 1989. 50p.

GOETZKE,S. Estudo Fitossociológico de uma Sucessão Secundária no Noroeste do Paraná, Proposta para Recuperação de Áreas Degradadas. Tese de Mestrado. UFPR, Curitiba, PR, 1990. 238p.

KAGEYAMA, P.Y., REIS, A. \& CARPANEZZI, A.A. Potencialidades e Restrições da Regeneração artificial na recuperação de áreas Degradadas. In: Simpósio Nacional Recuperação de Áreas Degradadas. Universidade Federal do Paraná, Curitiba, Pr, 1990. 238p.

KÖPPEN.W. Das geographische system der klimate. Handbuch der Klimatologie. Borhtraeger. Berlim. 1938.

LEITÃO FILHO, H.F. (Org.) Ecologia da Mata Atântica em Cubatão. Campinas, Sp. Editora UNESP/Editora da Unicamp. 184p. 1993

SILVA, M.B.R. Fitossociologia da Vegetação Lenhosa de Restinga em Maricá, Rio de Janeiro. Tese de Mestrado. Universidade Federal do Rio de Janeiro, RJ, 1991. 147p.

UFPR Simpósio nacional recuperação de áreas degradadas. Anais..., UFPR, Curitiba, Pr. 520p. 1992

I Simpósio sul-americano e II simpósio nacional de recuperação de áreas degradadas. Anais ..., UFPR, Foz do Iguaçu, Pr, 679p. 1994. 
UFRRJ Workshop sobre recuperação de áreas degradadas. Anais..., UFRRJ, Itaguai, RJ, 202p. 1991.

VALCARCEL,R. Plano de Recuperação Ambiental Serviço de Engenharia RODOFÉRREA S.A. RJ, 1994. 64p. 